\title{
Redesigning Italy: The New Flow of Immigration
}

\section{by Guido Bolaffi}

Immigration will prove to be an extremely delicate problem for Italy during the coming years, one that is going to affect the political sphere as well as society and its institutions. The complex nature of entrance and settlement patterns of migrants in Italian cities is a phenomenon about which we still know very little. It will soon be seen that the makeshift measures that have hitherto been taken, in what can only be termed as a sort of political and administrative form of laissez-faire, will no longer be adequate. There are two primary reasons for this. First, Italy cannot adopt immigration policies which are not in conformity with those of other European nations. Second, and most important, the very nature of modern immigration represents a serious challenge to a bureaucracy like the one in Italy, which tends to be slow in making decisions and not very flexible when it comes to carrying them out.

Even though the geographical location of Italy-with its very long coastlines-may make it easier for illegal aliens to reach our shores, it is a gross exaggeration to claim, as some have done, that this per se constitutes an insurmountable obstacle to the control of immigration. One need only look at Great Britain which, despite the fact that it is an island, has for more than a century stringently regulated the access of foreigners to its national territory. In more blunt terms, the slackness and negligence which over the years have characterized our approach to immigration, as if we secretly hoped the problem would somehow go away by itself, shows just how influential certain sectors of the Italian political milieu continue to be. Specifically, these sectors, in order to avoid making tough or unpopular decisions, invariably choose the path of least resistance, preferring to pay increasingly more in terms of social costs and the dissipation of public resources.

The most recent and perhaps most significant example of this "thoughtlessness" on the part of our decision-makers may be seen in the political deadlock which has arisen between the government and various parliamentary groups over whether or not to grant yet another

* Capo dell'Ufficio Immigrazione del Ministero degli Affari Sociali; Roma, Italia (Director of the Immigration Department of the Ministry of Social Affairs of Italy, Rome, Italy). 
amnesty to illegal aliens already residing on Italian soil. One should consider this important point: the deputies in favor of amnesty do not belong to any one political group, nor do they share a common ideological or cultural bias; they form what is known as a cross-party party with members coming from every zone of the political spectrum from the Christian Democrats (the PDS), all the way to the extreme left. These political groups campaign inexplicably in favor of the same measure, each camp motivated by its own set of deep-rooted ideological prejudices. In no other country in the world would those in power have gone so far as to cast doubt on the very credibility of the institutions they represent by considering a measure which, without actually changing the existing legislation itself, would have pardoned those who had effectively broken the law and automatically penalized those who had obeyed it. In my view, this is an act of sheer irresponsibility, even more so if we consider just how controversial is the subject of immigration. When it comes to immigration, we have to be very careful. The recent electoral victories of right wing xenophobic parties in Europe should have made it clear that inter-ethnic conflict is not something which is confined to the economy alone; it has repercussions in the area of politics and culture as well, which could eventually trigger dangerous reactionary backlashes on the part of institutions and bring about a kind of "identity crisis" among groups which have traditionally been thought to be firm supporters of democracy.

If we look at those countries which have already had to deal with immigration in the past, we see immediately that there are no easy ways out, and no miraculous cures. No single piece of legislation, however well-framed, will be able to provide an ultimate solution. More than any other social issue, immigration has shown itself to be far more complex, and liable to change at a faster rate than the measures which have been taken by governments to cope with it. Immigrants themselves have been quick to take advantage of the inevitable loopholes in any law. The flexible nature of the problem poses serious challenges to the Italian bureaucracy which tends to insist that the letter of the law be respected, while often neglecting to enforce the spirit behind it or adapt itself concretely to an ever-changing situation. For example, despite the fact that two immigration bills have already been passed by Parliament, no one has yet been officially charged with the task of actually counting how many immigrants are entering the country. Perhaps even more surprising is that, despite the increasingly tighter policing of our borders, many immigrants continue to be listed as living in Italy long after they have decided to go back to their native countries. We seem to be interested in knowing who is coming in, but not in 
who is leaving. The outcome of this is that we cannot really say how many "legal" aliens there are or how many are unemployed because a number of them continue to show up on government employment agency lists when in reality they no longer reside in the country.

That there are "two Italies" holds true for immigration as well. In the industrialized North, foreigners are gradually taking advantage of the official placement agencies and the protection of trade unions. The South, on the other hand, continues to absorb ever-increasing numbers of illegal aliens who, upon arrival, vanish into the secret ranks of the unofficial, "under-the-table" labor market. This state of affairs was highlighted by the recent episodes of inter-ethnic violence which broke out in the regions of Foggia and Caserta. A recent report by the organization Federmeccanica on the state of the automobile industry also confirmed that integration of foreigners is taking place at "two speeds." Four and one-half percent of businesses were shown to have immigrants from outside the EEC on their payroll while the total number of immigrants in this sector was around one percent of all those employed. An interesting fact was that only a part of the jobs these immigrants actually performed were listed as menial or unskilled, while a not insignificant number of immigrants were in positions requiring medium or high level of skills. This is why trade unions and employers are currently negotiating agreements over how many immigrants can be hired in the factories. It also shows that the influx of foreign workers is not caused merely by a demand for unskilled labor, but by the existence of areas where professional training courses for Italian citizens have failed to meet the needs of the labor market. Foreigners thus constitute a shadow-labor force which serves as a kind of ballast and emergency reservoir.

Until recently, the phenomenon of immigration in Italy showed characteristics which were quite peculiar and unlike those of other industrialized nations. In other countries, foreign labor tended to gravitate to highly industrialized areas where factories were in need of workers that could no longer be found among the nationals. In Germany, France, and the United States, the governments herded new arrivals into those areas most needed by the economy. In Italy just the opposite occurred. A large number of immigrants found precarious, black-market type jobs in regions of the country which were the least industrialized and had the highest levels of unemployment. This rather paradoxical situation was brought about by the sort of off-hand deregulation with which our government attempted to manage the growing number of arrivals. In addition, despite the current recession, the economy in the North is nearly at full employment. This means that 
new vacancies in factories or in the service sector-and not just those positions requiring a low level of skills-are going to be taken by foreigners. Thus, it is hardly surprising that if companies in the North are able to tap this reservoir of foreign workers, there will not be any more incentive for them to set up plants and create jobs in the South where unemployment is high; the nearly two million Southern Italians who are out of work will, as a result of immigration, be simply passed over. We should not underestimate another negative effect that the growing presence of illegal aliens will have on the South's shaky economic development. Recent studies have shown that the presence of "first generation migrants," many of whom are without working papers and who are ready to take any sort of job whatever the salary, has negative economic consequences. Specifically, such a situation tends to have a slow-down effect on the modernization process of traditional types of businesses, encourages the "black-market" economy, and in some cases even encourages businesses to go "under-the-table." The reason for this is that while the presence of foreigners has little effect on official union-backed wage negotiations, the tendency is for foreigners to undercut wages in the non-official sectors of the economy.

Italy, unlike other countries with a strong democratic tradition, has not yet given birth to any nation-wide anti-immigrant movement which is ready to capitalize on the potential animosity out-of-work Italians might feel against foreigners. The simple reason for this is that the most backward and conservative elements of the economy, because they know how important this ethnic reservoir is, have set themselves up as liberal champions of immigrants and oppose any attempts by the government to get a handle on the problem. What is the result of all this? We have a unanimous facade of anti-racism, a complete consensus, where everybody agrees with everybody else and there is no opposition. This is a process of political camouflage which the ruling classes of the South have been known to adopt and which up to now has been successful because of the specific political conditions of our country. Until very recently, Italy has been a country which exported immigrants, a fact which has inspired a sense of "incomprehensible solidarity" among organizations like the confederate trade unions which, unlike unions in other countries, support an open-borders policy and multi-cultural integration. Our decision makers, both from the left and right side of the political spectrum, simply do not know what to make of a situation where Italy, for the first time in history, is actually attracting brains and brawn from abroad. So, except for some vague threats coming from Umberto Bossi's Lombard League, everybody seems to agree that immigration is a good thing. In fact, however, there are growing differences between those in favor of a more disci- 
plined approach and those who think that we should simply let everybody in. What is behind all this?

The recent massive waves of immigration have created two main problem areas which Italy must face. One has to do with politics and culture, the other concerns socio-economic questions. Even though these two areas are interrelated, the potential dangers inherent in each are different, with some being more urgent and others less so. It stands to reason, therefore, that any policy aimed at integrating immigrants is going to have to take all of this into account. Millions of people of different races and creeds, with customs vastly different from our own, people who do not even eat the same food as we do, are bound to have an enormous and permanent impact on the way we define ourselves and our national identity. This is not going to be an easy or painless process. It is going to be complex and no one can stop it. Even the future of our democracy is going to be influenced by it. Therefore, people who look at the problems exclusively in terms of economics and statistics are missing the point, as are those who see the problem as a purely cultural one. Neither attitude is going to be particularly effective if we wish to prevent the outbreaks of racial violence that continue to occur in other countries. In the struggle to stamp out racism, should not we err on the side of doing more rather than doing less?

Another potential for conflict comes from the supporters of an open-borders policy, who in the name of the high-sounding ideals of multi-racial and multi-ethnic society say that everybody should be permitted to come. There is something "radically chic" about this position. It is a kind of "ivory-tower" intellectualism which fails to take into account the very unpleasant reality of the hand-to-mouth existence many clandestine immigrants actually lead and the daily humiliation and exploitation they have to endure, which for many women can mean physical or even sexual violence. This is especially true in the South, where the state is not yet in the position of being able to guarantee even the most basic rights, such as jobs or social services, even to Italians themselves. It is better not to unduly inflame the public by using expressions like "free immigration," as if we could simply ignore the necessity for economic integration and the availability of social services. Multi-racial, multi-ethnic societies are only possible where there is a social contract in existence which regulates interchange between members of a society which has rules and in which everyone respects the law. This can only come about if people are committed to building a common future together.

Is Italy going to be able to consolidate its diverse views to create a policy on immigration? This is starting to look less like an ideal goal and more like a dire necessity, given the explosive growth of the 
phenomenon. Success is by no means certain. First, the problem is of an entirely different order, the likes of which we have never had to deal with before. There is a kind of "Protean" double nature to it, in that, as it grows quantitatively, it also transforms qualitatively. If immigrants represent a structurally permanent and growing part of the labor market-a fact which the government seems only recently to have discovered-the character of immigrant labor is in a state of continuous flux. The most important reason for alarm, however, is the wide gap existing between the obsolete means the state has at its disposal and the kind of problems that have to be addressed. Until recently, Italy was alone among the industrialized countries to be spared this dubious by-product of prosperity. The waves of foreigners from the Third World or Eastern Europe storming at our gates are a sign that Italy has definitively joined the ranks of the affluent nations of the "North." But unlike them, our institutions are still lagging far behind. The danger is that they will not be up to the task of handling a phenomenon which is having such an enormous impact on our economy and our society. If a country does decide to open up its borders to immigrants, three essential things are necessary.

First, a central authority or body must exist whose job it is to coordinate the implementation of social and economic policy and which is equipped to control migrant flows into and out of the country. Under the new ministry of Social Affairs, an agency like this is already in its early stages and, before long, could be working to full capacity. Second, the nature of immigration and the fact that more family groups will be arriving means that different branches of the public administration will have to become active simultaneously; organizations representing education, labor, social affairs, health and justice will have to work together and not simply ignore each other-or even worse, compete. Third, the passing of the Martelli law means that the age of makeshift measures and last minute improvisation has definitely come to an end and a new, tough era has begun.

Italy will have to decide who it wants to let in and on what criteria such entrance should be based. Above all, Italy will have to come up with some kind of policy for integrating foreigners so that those people who in the next few years do decide to settle down in Italy know just where they stand. 